\title{
Isolation, Characterization and Mode of Action of a Plant-Derived Antifungal Peptide, Cc-AFP1 Against Aspergillus Fumigatus
}

\author{
Sima Sadat Seyedjavadi \\ Pasteur Institute of Iran \\ Soghra Khani \\ Pasteur Institute of Iran \\ Mehdi Goudarzi \\ Shahid Beheshti University of Medical Sciences \\ Hadi Zare-Zardini \\ Shahid Sadoughi University of Medical Sciences and Health Services \\ Masoomeh Shams-Ghahfarokhi \\ Tarbiat Modares University \\ Fatemehsadat Jamzivar \\ Pasteur Institute of Iran \\ Mehdi Razzaghi-Abyaneh ( $\nabla$ mrab442@yahoo.com) \\ Pasteur Institute of Iran
}

\section{Research Article}

Keywords: Antifungal peptide, Aspergillus fumigatus, Carum carvi, Cytotoxicity, Mechanism of action, Fungal infections

Posted Date: June 7th, 2021

DOI: https://doi.org/10.21203/rs.3.rs-571433/v1

License: (c) (i) This work is licensed under a Creative Commons Attribution 4.0 International License. Read Full License 


\section{Abstract}

Among novel molecules with therapeutic efficacy, antifungal peptides (AFPs) have recently been attracted due to their unique ability to evade fungal pathogens. In this study, a novel AFP, Cc-AFP1 (MW $3.759 \mathrm{kDa}$ ) isolated from Carum carvi L. was purified by precipitation and chromatography techniques. Sequence analysis by Edman degradation revealed a fragment of 36 amino acid residues as RVCFRPVATYLGVCGVSGACRDHCVKLGSCVYKGPG. The tertiary structure prediction using the I-TASSER showed a-helix and random coil structure. Cc-AFP1 had a net charge of +4 and hydrophobicity ratio of $44 \%$. The antifungal activity of Cc-AFP1 was confirmed against Aspergillus species with MIC values in the range of 8-16 $\mu \mathrm{g} / \mathrm{mL}$. Cc-AFP1 had less than $5 \%$ hemolytic activity at 8-16 $\mu \mathrm{g} / \mathrm{mL}$ on human red blood cells, while it was nontoxic for HEK293 cell lines. Stability analysis showed that Cc-AFP1 activity was maintained at different temperatures $\left(20\right.$ to $\left.80^{\circ} \mathrm{C}\right)$ and pH (8 to 10$)$. The results of a propidium iodide uptake and transmission electron microscopy showed that the antifungal activity of Cc-AFP1 could be attributed to altering the fungal cell membrane permeability. Taken together, these results indicate that Cc-AFP1 may be an attractive molecule to develop as a novel antifungal agent combating fungal infections cause by Aspergillus species.

\section{Introduction}

In two past decades, there has been an increase in life-threatening fungal infections leading to high prevalence of morbidity and mortality ${ }^{1}$. Also, the increased rate of immunocompromised patients has led to more serious fungal infections ${ }^{2,3}$. Over 2 million people are affected annually by invasive fungal diseases all over the world while fungal diseases cause more deaths every year compared with either tuberculosis or malaria ${ }^{2}$. Invasive aspergillosis with more than $80 \%$ mortality rate is one of the most important nosocomial fungal infections caused mainly by $A$. fumigatus, followed by some other Aspergilli such as $A$. flavus as the second etiologic agent ${ }^{4}$. Despite the increasing rate of fungal infections, and limited availability of effective antifungal drugs, only a few new antifungals have been developed into the market in recent years. Emerging antifungal drug resistance strengthens the need for the novel antifungal molecules development as well ${ }^{5,6}$. Ideally, novel antifungal agents should have a broad-spectrum activity, being targetspecific with multiple mechanisms of action without cross-resistance among fungal species. Among naturally occurring bioactive compounds with medicinal properties, antimicrobial peptides (AMPs) raised increasing attention due to their potent antimicrobial activity and simple structure ${ }^{7}$.

In this context, antifungal peptides (AFPs) originated from natural sources such as plants and microorganisms gained increasing attention as therapeutic agents in recent years owing to several advantages, including highly selectivity and effectiveness, low immunogenicity, and good penetration to host organs and tissues ${ }^{8}$. Antifungal peptides are diverse groups that are classified according to source, structure and mode of action ${ }^{6,7}$. Natural AFPs are produced by many organisms, like vertebrate and invertebrate animals, plants and microorganisms and have a linear or cyclic structure with hydrophobic or amphipathic properties ${ }^{9-11}$. Based on the mechanism of action, antifungal peptides are divided into cell membrane-and intracellular-targeting peptides 12,13

The purification and identification of novel antifungal peptides have always been of interest in the current era of innovative therapies and management of human fungal pathogens ${ }^{14}$. Plants produce a large variety of AFPs that have the potential to be used in the development of novel antifungal therapeutics ${ }^{15}$. These peptides are cysteine- rich and commonly found in seeds and, based on amino acid sequence homology, comprise a number of classes ${ }^{16}$.

Carum carvi L. (caraway) is an annual herbaceous plant that belongs to the Umbelliferae family. The plant is native to some certain regions of Iran and is used in foods and herbal medicine ${ }^{17-19}$. To our knowledge, very little has been documented about AFPs originated from $C$. carvi. In the present study, we isolated and characterized a novel AFP from $C$. carvi seeds with a a-helix and random coil structure which showed strong antifungal activity against human and animal pathogenic Aspergillus species, while it has no obvious cytotoxicity against human red blood cells and HEK293 cell line in vitro.

\section{Materials And Methods}

\section{Fungal strain and Carum carvi}

Carum carvi seeds were prepared from the herbarium of the Research Institute of Forests and Rangelands (RIFR), Tehran, Iran. The plant material was identified by V. Mozaffarian and a voucher specimen was deposited at RIFR under the Voucher Number of TARI-51257. Aspergillus species including A. fumigatus Af293, A. niger ATCC 9029, and A. flavus PFCC 100C were provided by the Pathogenic Fungi Culture Collection of the Pasteur Institute of Iran (http://fa.pasteur.ac.ir/VisitDetails.aspx?Id=1311). The strains were kept in Sabouraud dextrose broth (SDB, Merck, Germany) including 20\% glycerol at $70^{\circ} \mathrm{C}$. The strains were subcultured in Sabouraud dextrose agar (SDA, Merck, Germany). Carum carvi seeds were purchased from the market and stored at room temperature.

\section{Peptide extraction and purification}

In brief, Carum carvi seeds were ground to a fine flour, and extracted with an extraction buffer $\left(100 \mathrm{mM} \mathrm{KCl} 15 \mathrm{mM} \mathrm{NaH}_{2} \mathrm{PO}_{4}, 10 \mathrm{mM} \mathrm{Na} 2 \mathrm{HPO}_{4}\right.$, and $1.5 \%$ EDTA) $\mathrm{pH} 5.4$, in the shaker at $4^{\circ} \mathrm{C}$ for $4 \mathrm{~h}^{33}$. Subsequently, the supernatant was filtered (Whatman filter paper, USA) and saturated with $85 \%$ ammonium sulphate $\left(\left(\mathrm{NH}_{4}\right)_{2} \mathrm{SO}_{4}\right)$. The precipitate, formed overnight, was dialyzed against distilled by using benzoylated membrane performance (MWCO 2,000 Da) (Sigma Aldrich-USA). For isolating low molecular weight peptides, the protein extract was filtered through AmiconUltra-15ml 10,000 MWCO centrifugal filters (Millipore- USA) followed by lyophilization. The reverse phase HPLC column (C18 column, $7.8 \times 300 \mathrm{~mm}$; Tosoh, Tokyo, Japan) with the gradient of $5 \%-65 \%(\mathrm{v} / \mathrm{v})$ solution $\mathrm{B}(0.098 \%$ TFA in acetonitrile) and $\mathrm{A}(0.1 \%$ TFA in water) at a flow rate of $1 \mathrm{~mL} / \mathrm{min}$ for 85 min was employed for purifying the 
antifungal peptides from lyophilized extracts ${ }^{34}$. According to the absorbance at $220 \mathrm{~nm}$, the peaks were collected and then lyophilized for determining the antifungal effect and those that had the highest activity were collected. For checking the peak with antifungal activity purity, this peak was rechromatographed in the same column using the similar solvent system in the same conditions.

\section{SDS-PAGE}

For evaluating the molecular weight as well as the purity of the peak with antifungal activity, we performed the tricine-sodium dodecyl sulfatepolyacrylamide gel electrophoresis (Tricine-SDS-PAGE) under reducing conditions on a Bio-Rad electrophoresis apparatus based on the Schagger approach

${ }^{35}$. Products were run on a $12 \%$ tris-tricine gel with tricine-SDS running buffer for overnight in $25 \mathrm{~V}$ tension and then the gel was stained with silver staining. Protein ladder (2-250 KDa) was used as a standard for determining proximate molecular mass.

\section{Radial diffusion assay}

The antifungal activity of the collected peaks was assessed using a radial diffusion assay (RDA) according to the Wang approach ${ }^{36}$. The Aspergillus species spore suspension was obtained a scraping the culture surface slightly by a sterile glass rod following the addition of enough $0.1 \%$ aqueous solution of Tween 80 . Briefly, fungal cells were added to Sabouraud dextrose agar fixed at $42^{\circ} \mathrm{C}$ followed by a quick dispensing into a Petri dish. The wells were punched and the peptide was loaded into the wells. Following incubation $\left(35^{\circ} \mathrm{C} / 48 \mathrm{~h}\right)$, the clear zones around the wells were assessed. Amphotericin B was considered as a positive control. All the experiments were

\section{Minimum inhibitory concentrations (MICs) and minimum fungicidal concentrations (MFCs)}

The minimum inhibition concentration assay (MIC) of the purified and active peptide was measured as described by Li et al ${ }^{37}$ after some corrections. In brief, the assay was determined by an inoculum of $10^{5}$ conidia/ $\mathrm{mL}$ in Sabouraud Dextrose Broth and evaluated in 96-well micro plates. Serial 2-fold dilutions were provided for obtaining final levels ( 1 to $250 \mu \mathrm{g} / \mathrm{mL}$ ). Amphotericin B $(0.016$ to $4 \mu \mathrm{g} / \mathrm{mL})$ was used as control. Incubation of the plates was done $\left(35^{\circ} \mathrm{C} / 48 \mathrm{~h}\right)$. The minimum inhibitory concentration (MIC) was defined as $99 \%$ inhibition of fungal growth in 96 -well micro plates by visual assay. 20 $\mu \mathrm{L}$ of the specimens of each well was then isolated and plated on Sabouraud dextrose agar plates. The plates were incubated at $35^{\circ} \mathrm{C}$ for $48 \mathrm{~h}$. The minimum fungicidal concentration (MFC) was defined as the lowest peptide level to kill fungal cells.

\section{Mass spectrometry and $\mathrm{N}$-terminal sequence analysis}

Molecular masse of the isolated antifungal peptide was determined by electro-spray ionization mass spectrometry (MS) at a mass to charge ( $\mathrm{m} / \mathrm{z}$ ). Amino acid sequence of the purified antifungal peptide was determined using Edman degradation. Accordingly, an ABI Procise Edman Micro Sequencer (Model 492) was connected online to the $140 \mathrm{C}$ ABI PTH Amino Acid Analyzer.

\section{Sequence alignment and phylogenetic tree}

The search for similar sequences was performed by database search (for find similar peptides with highest similarity to new peptide) and CLC main workbench software. In this section, 13 peptides with highest similarity to new peptide were obtained after database search. Program blast was done for comparison of the sequences of these peptides with new peptide. Alignment was manually adjusted and phylogenetic tree was acquired by CLC main workbench software. For evaluation of reproducibility of the tree topology, phylogenetic tree was measured using bootstrap analysis with 100 replications.

\section{Bioinformatics analysis}

For general AMP prediction, APD3 prediction server (https://wangapd3.com/main.php) was used. AMP probability of the peptide was anticipated through machine learning algorithms support vector machine (SVM), artificial neural network, random forest, and discriminant analysis using the $\mathrm{CAMP}_{\mathrm{R} 3}$ server (http://http://www.camp3.bicnirrh.res). Each algorithm threshold was from 0.5 to 1 . Peptides with the threshold number of $>0.5$ were AMP. The physicochemical characteristics of antifungal peptide were predicted using ExPASy Proteomics server (http://www.expasy.org/tools/protparam. html) for the net charge, hydrophobic ratio, Boman index, isoelectric point (pl), values of the instability index, aliphatic index, and molecular weight. To predict the antifungal activity of the expected peptide the online server iAMPpred (http://cabgrid.res.in:8080/amppred/server.php) was used. Helical wheel projection was done for predicting the amino acid position in peptides using Heliquest server (https://heliquest.ipmc.cnrs.fr/cgi-bin/ComputPara ms.py). The threedimensional structure of the peptide was estimated online by the I-TASSER server (http://zhanglab.ccmb.med.umich.edu/ITASSER/). The model quality was measured through Accelrys, DS visualizer ver. 1.7. BLAST indicated the similarity between the peptide and other AMPs in APD3 database. To predict the hemolytic property of the peptide the HemoPI server (https: //crdd.osdd.net/ragha va/hemop i/design n.php) was used (SVM score ranges between 0 and 1, i.e., 1 very likely to be hemolytic, 0 very unlikely to be hemolytic) ${ }^{38}$.

\section{Peptide synthesis}

The peptide was chemically synthesized by Biomatik Co. (Ontario, Canada) using 9-fluorenylmethoxycarbonyl (F-moc) solid-phase chemistry ${ }^{39}$. Peptide purity and mass identity were confirmed by reversed-phase high-performance liquid chromatography (RP-HPLC) and electrospray ionization-mass spectrometry (ESI-MS, Waters ZQ2000, Milford, MA, USA), respectively.

\section{Hemolytic activity}


The peptide hemolytic activity was calculated according to Wu et al. ${ }^{40}$. Fresh heparinized human whole blood prepared from Department of Cell Bank of the Pasteur Institute of Iran was centrifuged for $5 \mathrm{~min}$ at $4^{\circ} \mathrm{C}$. The resultant erythrocytes were washed three times followed by suspending in PBS. Then, the peptide serial dilution $(1-128 \mu \mathrm{g} / \mathrm{mL})$ was mixed with erythrocytes and subjected to incubation $\left(1 \mathrm{~h} / 37^{\circ} \mathrm{C}\right)$. Erythrocytes after treatment with PBS were applied as a negative control and $0.1 \%$ Triton X-100 as positive control. Hemoglobin release was measured through the measurement of the absorption at $567 \mathrm{~nm}$ using the ELISA reader. The amount of hemolysis was calculated by the following formula:

Hemolysis $(\%)=[$ test OD - negative control OD $) /($ positive control OD - negative control OD $)] \times 100$.

\section{Cytotoxicity Assays}

The cytotoxic effects of the antifungal peptide on Human Embryonic Kidney cell line 293 (HEK293) prepared from Department of Cell Bank of the Pasteur Institute of Iran was calculated by 3-(4,5-dimethylthiazol-2-yl)-2,5-diphenyltetrazolium bromide (MTT) assays ${ }^{41}$. In brief, Dulbecco's modified Eagle's medium (DMEM) treated with $10 \%\left(\mathrm{v} / \mathrm{v}\right.$ ) fetal bovine serum (FBS) was used for growing of the cell lines and was subjected to incubation with $5 \% \mathrm{CO}_{2}$ at $37^{\circ} \mathrm{C}$. Seeding the cells was done by plates of 96 wells with about 5,000 cells per well. Following overnight culture at $37^{\circ} \mathrm{C}$ in $5 \% \mathrm{CO}_{2}$, different peptide levels $(1-128 \mu \mathrm{g} / \mathrm{mL}$ ) were used for the treatment of the cells for $24 \mathrm{~h}$. Next, incubation was done c using $50 \mathrm{ml}$ of $\mathrm{MTT}$ ( $0.5 \mathrm{mg} / \mathrm{mL}$ ) for $4 \mathrm{~h}$. Following incubation, the plates were centrifuged ( $5 \mathrm{~min}$ ), and the supernatants were removed, and for dissolving the formazan crystals, DMSO (dimethyl sulfoxide; $150 \mathrm{~mL}$ ) was added. At the end, the ELISA reader was used to measure the absorbance at $570 \mathrm{~nm}$. The findings were obtained from three separate experiments, each conducted in triplicate.

\section{Temperature and pH stability assay}

The peptide stability at different temperatures and $\mathrm{pH}$ values was calculated as defined by ${ }^{42}$. Heat sensitivity was evaluated after incubation at various temperatures $\left(10-100^{\circ} \mathrm{C}\right)$ for $1 \mathrm{~h}$. The peptide without heating at various temperatures was considered as a control. For $\mathrm{pH}$ stability testing, the samples were adjusted to $2-10$ with $1 \mathrm{~mol} / \mathrm{I} \mathrm{HCl}$ or $1 \mathrm{~mol} / \mathrm{I} \mathrm{NaOH}$ and placed at $25^{\circ} \mathrm{C}$ for $1 \mathrm{~h}$. Then, the $\mathrm{pH}$ value was fixed at 7.0 before antifungal assays. The peptide dissolving in solution ( $\mathrm{pH}:$ 7.2) was considered as a control. The tests were performed three times. A. fumigatus was applied as an indicator for detecting the antifungal activity that was assessed using radial diffusion assay.

\section{Determination of fungal cell integrity using PI uptake}

To determine the membrane permeability of the antifungal peptide on $A$. fumigatus hyphae, the propidium iodide (PI) uptake assay was used according to the Fluorescence microscopy assay.

In brief, a conidia suspension of $A$. fumigatus $\left(10^{6}\right.$ conidia/ $\left.\mathrm{mL}\right)$ in SDB was poured on a 6-well micro plate and incubated $\left(35^{\circ} \mathrm{C} / 24 \mathrm{~h}\right)$. Next, the hyphae were incubated with the antifungal peptide at the concentration of MIC and $2 \times \mathrm{MIC}$ for $4 \mathrm{~h}$ at $35^{\circ} \mathrm{C}$ via constant shaking (120 rpm). Subsequently, the $\mathrm{PI}$ solution with a final concentration of $50 \mu \mathrm{g} / \mathrm{mL}$ was added to each well for $15 \mathrm{~min}$ at room temperature in the dark. Next, the stained hyphae specimens were visualized by fluorescence microscopy (Eclipse 80i- Nikon-Japan) with appropriate filters (excitation/emission at 530/590 nm). Untreated fungal hypha was used as negative controls.

\section{Transmission Electron Microscopy (TEM)}

TEM was performed as described previously ${ }^{43}$ with some corrections. For evaluating the peptide effect on hyphae morphology, we cultured the conidia suspension of $A$. fumigatus $\left(10^{6}\right.$ conidia/mL) in SDB $(1 \mathrm{~mL})$ in microplates of 24 wells $\left(24 \mathrm{~h} / 35^{\circ} \mathrm{C}\right)$ followed by exposing to antifungal peptide at the concentration of $2 \times \mathrm{MIC}$ and incubation at $35^{\circ} \mathrm{C}$ for $4 \mathrm{~h}$. Then the specimens were fixed using $2.5 \%(\mathrm{v} / \mathrm{v})$ glutaraldehyde $\left(3 \mathrm{~h} / 4^{\circ} \mathrm{C}\right)$. Following three times washing in $0.1 \%$ PBS, the samples were then fixed using $1 \%$ osmium tetroxide in PBS within 70 min and were subjected to washing for two times with PBS dehydrated in gently increasing acetone solutions, and embedding in Epon 812. The ultra-microtome was used to cut ultrathin sections and staining with uranyl acetate and lead citrate was done, and observed by a Zeiss EM-900 TEM device at $80 \mathrm{kV}$. The non-treated hypha was considered as controls.

\section{Statistical analysis}

Values were expressed as mean \pm SD. Statistical analysis was done with graph pad prism5 Statistical software (GraphPad Software, Inc., La Jolla, CA, USA).

\section{Results}

\section{Peptide purification}

The low molecular weight peptides obtained from Carum carvi seeds was lyophilized and subjected to reversed-phase chromatography and after fractionation using a C18 column, 11 fractions were obtained (Figure 1a). All the fractions were collected from the C18 RP-HPLC as an individual peak to be tested for the antifungal activity against Aspergillus species (data are not shown in details). Out of 11 peaks, Peak 7 had a good antifungal activity. For more purification, this active peak with antifungal activity was applied again to the same column for rechromatography under the same elution conditions (Figure 1b). 


\section{SDS-PAGE}

Figure 1c indicates the electrophoresis pattern of the extracted peptides passed through an ultra-membrane with a $10 \mathrm{kDa}$ cut off and active peak with antifungal activity purified from the RP-HPLC column on the SDS-PAGE. Following the purification processes as well as SDS-PAGE analysis, a single band with a molecular weight of about $3.7 \mathrm{kDa}$ was obtained.

\section{Antifungal activity}

The antifungal activity of the isolated peaks from HPLC was measured against Aspergillus species based on RDA (data not shown). Accordingly, the inhibition zone diameter indicated that the peak NO. 7 could inhibit Aspergillus species growth when compared with AmpB as a common antifungal compound (Figure 2a) The diameter of the inhibition zones of Aspergillus species were 16-20 mm for the peptide, while they were 22-25 for AmpB (Figure 2b).

The peptide antifungal activity was more assessed as MIC values by micro broth dilution method. As shown in Table 1, the peptide was active against Aspergillus species, with MIC values that ranged $8-16 \mu \mathrm{g} / \mathrm{mL}$. Amphotericin B showed the MIC range of $0.25-0.5 \mu \mathrm{g} / \mathrm{mL}$ and the MFCs of the peptide against the Aspergillus species are equal or 2 times higher than its MICs.

Table $1 \mathrm{MIC}$ and MFC values $(\mu \mathrm{g} / \mathrm{mL}$ ) of Cc-AFP1 and amphotericin B (AmpB) for Aspergillus species

\begin{tabular}{|lllll|}
\hline \multirow{2}{*}{ Fungal strain } & \multicolumn{2}{l}{ MIC $(\mu \mathrm{g} / \mathrm{mL})$} & \multicolumn{2}{l|}{ MFC $(\mu \mathrm{g} / \mathrm{mL})$} \\
\cline { 2 - 6 } & Cc-AFP1 & AmpB & Cc-AFP1 & AmpB \\
\hline Aspergillus fumigatus Af293 & 8 & 0.5 & 16 & 0.5 \\
\hline Aspergillus flavus PFCC 100 & 16 & 0.5 & 32 & 1 \\
\hline Aspergillus niger ATCC 9029 & 8 & 0.25 & 8 & 0.5 \\
\hline
\end{tabular}

\section{Mass spectrometry and amino acid sequence}

Because of its antifungal activity, the peptide band of the peak $7(\sim 3.7 \mathrm{kDa}$ band $)$ was chosen for further characterization. ESI mass analyses of the purified peptide showed that the molecular mass of this peptide was $3759.43 \mathrm{Da}$ (Figure 1d). The result was in close agreement with the relative molecular weight indicated by Tricine- SDS- PAGE. To determine the amino acid sequence, the peptide was sequenced via Edman degradation. From this analysis a fragment of 36 amino acid residues was obtained as RVCFRPVATYLGVCGVSGACRDHCVKLGSCVYKGPG.

\section{Sequence alignment and phylogenetic tree}

The obtained peptide sequence indicated no full sequence homology to the reported AMPs and BLAST results further confirmed that this peptide was a novel antifungal peptide from Carum carvi seeds. Sequence alignment and phylogenetic tree showed that the new peptide has the highest sequence similarity (40\%) with Ac-AFP4 purified from Blue Flax (Heliophila coronopifolia) (Figure 3a, b) ${ }^{20}$. Based on this similarity and source of peptide purification (Carum carvi), this new peptide was named Cc-AFP1.

\section{Bioinformatics and structural analysis}

Generally, based on the predictions of online servers of $\mathrm{CAMP}_{\mathrm{R} 3}$ (Table 2) and iAMPpred indicated that Cc-AFP1 is AMP and has antifungal activity. The sequences and key physicochemical properties of Cc-AFP1 are summarized in Table 2. Table 2 presents the sequences and key physicochemical characteristics of Cc-AFP1. Cc-AFP1 is a small peptide that has 36 amino acids and its net charge, hydrophobic residue, protein- binding potential (Boman index), and pl were equal to, $+4,44 \%, 0.72$, and 9.04 , respectively.

Table 2 The probability of antimicrobial activity and physicochemical features of Cc-AFP1

\begin{tabular}{|c|c|c|c|c|c|c|c|c|c|}
\hline \multirow[t]{2}{*}{ Sequence } & \multirow{2}{*}{$\begin{array}{l}\% \\
\text { Hydrophobic }\end{array}$} & \multirow{2}{*}{$\begin{array}{l}\text { Net } \\
\text { charge }\end{array}$} & \multirow{2}{*}{$\begin{array}{l}\text { Boman } \\
\text { index }\end{array}$} & \multirow{2}{*}{$\begin{array}{l}\text { Molecular } \\
\text { weight } \\
\text { (Da) }\end{array}$} & \multirow{2}{*}{$\begin{array}{l}\text { Instability } \\
\text { index }\end{array}$} & \multirow{2}{*}{$\begin{array}{l}\text { Aliphatic } \\
\text { index }\end{array}$} & \multicolumn{3}{|c|}{ Score of algorithms } \\
\hline & & & & & & & SVM & RF & ANN \\
\hline RVCFRPVATYLGVCGVSGACRDRCVKLGSCVYKGPG & 44 & 4 & 0.72 & 3759.43 & 25.43 & 75.56 & 0.96 & 0.98 & AMP \\
\hline
\end{tabular}

The value of the instability index and aliphatic index for this peptide were 27.52 and 75.56 , respectively. The helical wheel diagram of Cc-AFP1 peptide showed this peptide adopted a-helix conformation and possessed a hydrophobic face (Figure 3c). The tertiary structure prediction using the server ITASSER showed a-helix and random coil structure in the Cc-AFP1 peptide (Figure 3d). The C-score can be used to estimate the quality of anticipated 
models using I-TASSER (in the range of -5.0 to 2.0). The considered C-score of Cc-AFP1 was 0.3 , which indicated the model correct global topology. CcAFP1 peptide showed a low hemolytic score (0.47), which indicated that it was low toxic.

\section{Hemolytic activity and cytotoxicity}

The Cc-AFP1 hemolytic activity was measured in human erythrocytes. As shown in Figure 4a, the Cc-AFP1 toxicity at its MIC (8-16 $\mu \mathrm{g} / \mathrm{mL})$ and MFC (16$32 \mu \mathrm{g} / \mathrm{mL})$ ranges were less than $5 \%$. Cc-AFP1 induced $12.56 \%$ of hemolytic activity at the highest tested concentration $(128 \mu \mathrm{g} / \mathrm{mL})$.

\section{Cytotoxicity}

The toxicity of the Cc-AFP1 against HEK293 cells was assessed by serial peptide levels ranged between 2 and $128 \mu \mathrm{g} / \mathrm{ml}$ (Figure 4b). Cc-AFP1 had a low (>6) toxicity against HEK293 cells at $8-32 \mu \mathrm{g} / \mathrm{mL}$.

\section{Effects of temperature and $\mathrm{pH}$ on antifungal activity}

We measured the effect of temperature on the Cc-AFP1 (Figure 4c) and based on the findings, Cc-AFP1 was stable at various temperatures $\left(20\right.$ to $80^{\circ} \mathrm{C}$ ) for $1 \mathrm{~h}$. Interestingly, a low reduction of $21.6 \%$ for $A$. fumigatus was observed at $100^{\circ} \mathrm{C}$ during $1 \mathrm{~h}$ of treatment.

Figure $4 \mathrm{~d}$ indicates the $\mathrm{pH}$ effects on the antifungal peptide stability. Cc-AFP1 remained stable at pH values ranging from 8 to 10 . However, its activity was reduced at $\mathrm{pH} 2,4$ and 6.0 .

\section{Effects of the peptide on cell membrane permeability}

The effect of Cc-AFP1 on the integrity of hyphae membrane of $A$. fumigatus was investigated using the PI uptake procedure by fluorescence microscopy. PI (a DNA-staining fluorescent probe) could enter the cell when the cell membranes is damaged and bind with nucleic acids and producing a red fluorescence. As shown in Figure 5, the fluorescent intensity increased in the hyphae of $A$. fumigatus when the Cc-AFP1 concentration was increased from $8 \mu \mathrm{g} / \mathrm{mL}(1 \times$ $\mathrm{MIC})$ to $16 \mu \mathrm{g} / \mathrm{mL}(2 \times \mathrm{MIC})$, however, there was no fluorescence in the control. The result of PI uptake indicated that Cc-AFP1 could disrupt the integrity of the cell membrane.

\section{Morphological observation}

According to Figure 6, untreated hypha of $A$. fumigatus had intact cell walls, integrated cell membranes and normal organelles (Figure 6a). In contrast, in treated hyphae with Cc-AFP1, pathologic ultrastructure changes including attenuated irregular cell wall, loss of the structural integrity and shrunk of the cell membrane, detachment of the cell membrane from the cell wall, cytoplasmic depletion and membranous damage of cytoplasmic organelles such as mitochondria were evident (Figure 6b, c).

\section{Discussion}

The diversity of AMPs in plants is large and so far hundreds of different peptides have been characterized. The present work focused on the isolation, purification, characterization and mechanisms of in vitro of a novel antifungal peptide, Cc-AFP1, in the protein extract of Carum carvi seeds. According to the BLAST results, Cc-AFP1 showed no complete sequence homology to any reported AMPs from AMPs databases, which strongly indicates that it is a new plant antifungal peptide from Carum carvi seeds.

In our research, in silico predictive and the physicochemical properties of Cc-AFP1 was investigated by several online tools before proceeding with the in vitro experiments. Cc-AFP1 consists of 36 amino acids in total with a net charge of +4 which is important to interact electrostatically with the negative charges of fungal membrane components ${ }^{21}$.

Cc-AFP1 also contains eight hydrophobic residues with a total hydrophobic ratio of $44 \%$, which facilitated the AMP-membrane interaction and disrupted the integrity of fungal membrane. Studies showed that hydrophobicity is one of the important parameters of AMP activity 21,22 Hydrophobic residues are needed to interact with the lipid bilayer to create pores in the fungal cell cytoplasmic membrane. Finally, such interactions degrade the fungal cytoplasmic membrane where the non-polar face of the AMP can be inserted into the membrane by hydrophobic interactions ${ }^{22}$. The Boman index of Cc-AFP1 is 0.72 $\mathrm{kcal} / \mathrm{mol}$ and the positive Boman index can increase the Cc-AFP1 capacity to attach to fungal cell membrane proteins ${ }^{23}$. This index can estimate the protein ability to attach to another protein ${ }^{24}$. The instability index is 27.52 ; this value indicates the stability of the peptide in a test tube which should be less than 40 . Furthermore, the Aliphatic index is 75.56 that is linked to thermo stability, is considered as the relative volume of side chains (Ala, Val, lle and Leu) 25 .

Structure prediction by the helical wheel projection (Fig. 3c) illustrated that some hydrophobic residues such as tree valine, leucine, and cysteine, accumulated in the one side of the structure and this may lead to facilitate the insertion of the non-polar face of the antifungal peptide into the membrane via hydrophobic interactions. On the other hand, accumulation of positive polar amino acids is evident on one side of the structure and the positive polar face can support phospholipid binding after the attachment of AMP to the cell membrane ${ }^{23}$.

According to the Sequence alignment and phylogenetic tree results, Cc-AFP1 showed the highest sequence similarity (40\%) with Hc-AFP4 antifungal peptide from plant source. Hc-AFP4 was isolated from Blue Flax and showed an effective antifungal activity against fungi such as Fusarium solani and 
Botrytis cinerea. The net charge as well as percentage of hydrophobic residue of Hc-AFP4 was +5 and $39 \%$, respectively ${ }^{20}$. The prediction results and physiochemical properties of Cc-AFP1 make it a promising AFP candidate. In our studies, we also confirmed the in silico results experimentally.

In this paper, MICs and MFCs of Cc-AFP1 have been measured against Aspergillus species and Cc-AFP1 showed a remarkable inhibitory effect against Aspergillus species with the MICs range of $8-16 \mu \mathrm{g} / \mathrm{mL}$.

Antifungal peptides act via different mechanisms, like increasing permeability and disrupting of fungal membranes, reactive oxygen species generation and apoptosis or intracellular receptor binding ${ }^{26}$. In this study, Cc-AFP1 increased the membrane permeability, which was confirmed by PI uptake assay. Only dead fungal cells with damaged cell membranes can take up PI dye, and A. fumigatus treated with Cc-AFP1 was able to take up more PI dye than the control. Many studies have confirmed the cell membrane damage after treatment with AMPs by the PI uptake assay ${ }^{27-29}$. TEM results also demonstrated the induction of membrane damage and loss of cell surface integrity by Cc-AFP1. These results are comparable to many other studies used TEM to determine the damage present in the fungal cell membrane after treatment with AMP $^{28,30}$.

Overall, these observations and evidence indicate that membrane damage and permeabilization is one of the mechanisms of action of this new peptide that has been previously reported for many antimicrobial peptides ${ }^{31}$. However, it is hard to recognize the mode of action Cc-AFP1 and more studies should be done to better understand the exact targets of this peptide.

The AMPs therapeutic effects are associated with the AMPs cell selectivity, by which they destroy pathogens with no obvious cytotoxic effect to mammalian cells. Cell selectivity can evaluate the AMPs capacity to differentiate pathogens from host cells. As shown in Figs. 4a, Cc-AFP1 indicated a negligible (> 5\%) hemolytic activity against the studied RBCs in MIC $(8-16 \mu \mathrm{g} / \mathrm{ml})$ and MFC $(16-32 \mu \mathrm{g} / \mathrm{mL})$ range. At a concentration of above the 32 $\mu \mathrm{g} / \mathrm{ml}$, the cytotoxic effects of Cc-AFP1 were observed Cc-AFP1 demonstrated approximately $12.56 \%$ hemolysis at $128 \mu \mathrm{g} / \mathrm{mL}$. The hemolytic activity against human RBC is correlated to peptide hydrophobicity and previous studies showed that peptides characterized by high hydrophobicity have a tendency to penetrate deeply into the red blood cell membrane hydrophobic core and perform hemolytic activities ${ }^{32}$.

Besides cell selectivity of the AMPs, their stability is an important challenge to use them for therapeutic purposes. Adding co-solvents to peptide solutions have different effects, like denaturation or reduced activity. Surprisingly, the Cc-AFP1 antifungal activity was not obviously changed under a wide range of temperature and $\mathrm{pH}$. The thermal stability of Cc-AFP1 can be due to the nature and chemical structure of the peptide demonstrated by aliphatic indices, calculated by the APD databases.

Overall, Cc-AFP1 as a novel antifungal peptide with a-helix and random coil structure was isolated from Carum carvi seeds and characterized through reverse phase HPLC, and Edman degradation methods. Cc-AFP1 showed a remarkable antifungal activity against human pathogenic Aspergillus species, while it had no obvious hemolytic activity and cytotoxicity in vitro. Cc-AFP1 was shown to disrupt and damage the fungal cell wall and cell membrane, increased cell permeability and disrupted membranous structures of the fungal cells.. Taken together these results indicate that Cc-AFP1 may be an attractive molecule to develop as a novel antifungal agent combating fungal infections cause by Aspergillus species. Further works to investigate spectrum of antifungal activity and the exact mechanism of action and structure-activity relationship of Cc-AFP1 are recommended.

\section{Declarations}

\section{Ethic statement}

All experimental research and field studies on the plant Carum carvi (Voucher number \# TARI-51257) in this paper complied with relevant guidelines and legislation of Research Institute of Forests and Rangelands (RIFR), Iran. This study was approved by Ethic Committee of National Institute for Medical Research Development (NIMAD) under ethic number IR.NIMAD.REC.1396.121.

Acknowledgements. This work was supported by the Elite Researcher Grant Committee under award numbers 958634 and 963646 from the National Institute for Medical Research Development (NIMAD), Tehran, Iran to MRA.

Author contributions. SS and MR-A designed and conceived the study. SS, SK, MG, HZ-Z, MS-G, FJ and MR-A carried out the experiments and analyzed the data. SS and MR-A wrote the paper. All authors read and approved the final version of the manuscript. MR-A supervised the study.

\section{Additional information}

Competing interests. The authors declare no competing interests.

\section{References}

1. Thompson, G. R. et al. Isavuconazole treatment of cryptococcosis and dimorphic mycoses. Rev. Infect. Dis. 63, 356-362, https://doi.org/10.1093/cid/ciw305 (2016).

2. Brown, G. D. et al. Hidden killers: human fungal infections. Sci. Transl. Med. 4,

165rv113-165rv113

, https://doi.org/10.1126/scitranslmed.3004404 (2012). 
3. Armstrong-James, D., Meintjes, G. \& Brown, G. D. A neglected epidemic: fungal infections in HIV/AIDS. Trends. Microbiol. 22, 120-127, https://doi.org/10.1016/j.tim.2014.01.001 (2014).

4. De Cesare, G. B., Cristy, S. A., Garsin, D. A. \& Lorenz, M. C. Antimicrobial Peptides: a New Frontier in Antifungal Therapy. Mbio. 11, https://doi.org/10.1128/mBio.02123-20 (2020).

5. Chowdhary, A., Sharma, C. \& Meis, J. F. Azole-resistant aspergillosis: epidemiology, molecular mechanisms, and treatment. J. Infect. Dis. 216, S436S444, https://doi.org/10.1093/infdis/jix210 (2017).

6. Fernández de Ullivarri, M., Arbulu, S., Garcia-Gutierrez, E. \& Cotter, P. D. Antifungal peptides as therapeutic agents. Front. Cell. Infect. Microbiol. 10, 105, https://doi.org/10.3389/fcimb.2020.00105 (2020).

7. Cruz, J., Ortiz, C., Guzman, F., Fernandez-Lafuente, R. \& Torres, R. Antimicrobial peptides: promising compounds against pathogenic microorganisms. Curr. Med. Chem. 21, 2299-2321, https://doi.org/10.2174/0929867321666140217110155 (2014).

8. Denning, D. W. \& Bromley, M. J. How to bolster the antifungal pipeline. Science. 347, 1414-1416, https://doi.org/10.1126/science.aaa6097 (2015).

9. Tam, J. P., Wang, S., Wong, K. H. \& Tan, W. L. Antimicrobial peptides from plants. Pharmaceuticals. 8, 711-757, https://doi.org/10.3390/ph8040711 (2015).

10. Silva, P. M., Gonçalves, S. \& Santos, N. C. Defensins: antifungal lessons from eukaryotes. Front. Microbiol. 5, 97, https://doi.org/10.3389/fmicb.2014.00097 (2014).

11. Faruck, M. O., Yusof, F. \& Chowdhury, S. An overview of antifungal peptides derived from insect. Peptides. 80, 80-88, https://doi.org/10.1016/j.peptides.2015.06.001 (2016).

12. Lécorché, P. et al. Cellular uptake and biophysical properties of galactose and/or tryptophan containing cell-penetrating peptides. Biochim. Biophys. Acta. 1818, 448-457, https://doi.org/10.1016/j.bbamem.2011.12.003 (2012).

13. Li, J. et al. Membrane active antimicrobial peptides: translating mechanistic insights to design. Front. Neurosci. 11, 73, https://doi.org/10.3389/fnins.2017.00073 (2017).

14. Meneguetti, B. T. et al. Antimicrobial peptides from fruits and their potential use as biotechnological tools-a review and outlook. Front. Microbiol. 7, 2136, https://doi.org/ 10.3389/fmicb.2016.02136 (2017).

15. Campos, M. L., de Souza, C. M., de Oliveira, K. B. S., Dias, S. C. \& Franco, O. L. The role of antimicrobial peptides in plant immunity. J. Exp. Bot. 69, 4997-5011, https://doi.org/ 10.1093/jxb/ery294 (2018).

16. De Lucca, A. J. Antifungal peptides: potential candidates for the treatment of fungal infections. Expert. Opin. Investig. Drugs. 9, 273-299, https://doi.org/ 10.1517/13543784.9.2.273 (2000).

17. Panda, H. Handbook on spices and condiments (cultivation, processing and extraction). (Asia. Pacific. Business. Press. Inc. 2010).

18. Grigore, A. et al. Chemical analysis and antimicrobial activity of indigenous medicinal species volatile oils. Rom. Biotechnol. Lett. 17, 7620-7627 (2012).

19. Nasiri, S., Shams-Ghahfarokhi, M. \& Razzaghi-Abyaneh, M. Inhibitory effect of Carum carvi essential oils on growth of Candida albicans. Sci. J. Microbiol. 3, 74-77 (2014).

20. De Beer, A. \& Vivier, M. A. Four plant defensins from an indigenous South African Brassicaceae species display divergent activities against two test pathogens despite high sequence similarity in the encoding genes. BMC. Res. Notes. 4, 1-19, https://doi.org/10.1186/1756-0500-4-459 (2011).

21. Kim, H., Jang, J. H., Kim, S. C. \& Cho, J. H. De novo generation of short antimicrobial peptides with enhanced stability and cell specificity. J. Antimicrob. Chemother. 69, 121-132, https://doi.org/10.1093/jac/dkt322 (2014).

22. Chen, Y. et al. Role of peptide hydrophobicity in the mechanism of action of a-helical antimicrobial peptides. Antimicrob. Agents. Chemother. 51, 13981406, https://doi.org/10.1128/AAC.00925-06 (2007).

23. He, J., Luo, X., Jin, D., Wang, Y. \& Zhang, T. Identification, recombinant expression, and characterization of LGH2, a novel antimicrobial peptide of Lactobacillus casei HZ1. Molecules. 23, 2246, https://doi.org/10.3390/molecules23092246 (2018).

24. Boman, H. Antibacterial peptides: basic facts and emerging concepts. J. Intern. Med. 254, 197-215, https://doi.org/10.1046/j.13652796.2003.01228.x (2003).

25. Guruprasad, K., Reddy, B. B. \& Pandit, M. W. Correlation between stability of a protein and its dipeptide composition: a novel approach for predicting in vivo stability of a protein from its primary sequence. Protein. Eng. Des. Sel. 4, 155-161, https://doi.org/10.1093/protein/4.2.155 (1990).

26. Van der Weerden, N. L., Bleackley, M. R. \& Anderson, M. A. Properties and mechanisms of action of naturally occurring antifungal peptides. Cell. Mol. Life. Sci. 70, 3545-3570 https://doi.org/10.1007/s00018-013-1260-1 (2013).

27. Dathe, M. et al. General aspects of peptide selectivity towards lipid bilayers and cell membranes studied by variation of the structural parameters of amphipathic helical model peptides. Biochim. Biophys. Acta. 1558, 171-186, https://doi.org/10.1016/S0005-2736(01)00429-1 (2002).

28. Lyu, Y., Yang, Y., Lyu, X., Dong, N. \& Shan, A. Antimicrobial activity, improved cell selectivity and mode of action of short PMAP-36-derived peptides against bacteria and Candida. Sci. Rep. 6, 1-12, https://doi.org/10.1038/srep27258 (2016).

29. Li, L. et al. Mechanism of antifungal activity of antimicrobial peptide APP, a cell-penetrating peptide derivative, against Candida albicans: intracellular DNA binding and cell cycle arrest. Appl. Microbiol. Biotechnol. 100, 3245-3253, https://doi.org/10.1007/s00253-015-7265-y (2016).

30. Do Nascimento Dias, J. et al. Mechanisms of action of antimicrobial peptides ToAP2 and NDBP-5.7 against Candida albicans planktonic and biofilm cells. Sci. Rep. https://doi.org/10.1038/s41598-020-67041-210, 1-14 (2020). 
31. Maurya, I. K. et al. Antifungal activity of novel synthetic peptides by accumulation of reactive oxygen species (ROS) and disruption of cell wall against Candida albicans. Peptides. 32, 1732-1740, https://doi.org/10.1016/j.peptides.2011.06.003 (2011).

32. Jiang, Z. et al. Effects of hydrophobicity on the antifungal activity of a-helical antimicrobial peptides. Chem. Biol. Drug. Des. 72, 483-495, https://doi.org/10.1111/j.1747-0285.2008.00728.x (2008).

33. Games, P. D. et al. Isolation, characterization and cloning of a cDNA encoding a new antifungal defensin from Phaseolus vulgaris L. seeds. Peptides. 29, 2090-2100, https://doi.org/10.1016/j.peptides.2008.08.008. (2008).

34. Asoodeh, A., Zardini, H. Z. \& Chamani, J. Identification and characterization of two novel antimicrobial peptides, temporin-Ra and temporin-Rb, from skin secretions of the marsh frog (Rana ridibunda). J. Pept. Sci. 18, 10-16, https://doi.org/10.1002/psc.1409 (2012).

35. Schägger, H. \& Von Jagow, G. Tricine-sodium dodecyl sulfate-polyacrylamide gel electrophoresis for the separation of proteins in the range from 1 to 100 kDa. Anal. Biochem. 166, 368-379, https://doi.org/10.1016/0003-2697(87)90587-2 (1987).

36. Wang, K. et al. Antimicrobial peptide protonectin disturbs the membrane integrity and induces RoS production in yeast cells. Biochim. Biophys. Acta. 1848, 2365-2373, https://doi.org/10.1016/j.bbamem.2015.07.008 (2015).

37. Li, R. F. et al. Antiproliferative effect and characterization of a novel antifungal peptide derived from human Chromogranin A. Exp. Ther. Med. 10, 2289-2294, https://doi.org/10.3892/etm.2015.2838 (2015).

38. Chaudhary, K. et al. A web server and mobile app for computing hemolytic potency of peptides. Sci. Rep. 6, 1-13, https://doi.org/10.1038/srep22843 (2016).

39. Merrifield, B. Solid phase synthesis. Science. 232, 341-347, https://doi.org/10.1126/science.3961484 (1986).

40. Wu, X. et al. In vitro and in vivo activities of antimicrobial peptides developed using an amino acid-based activity prediction method. Antimicrob. Agents. Chemother. 58, 5342-5349, https://doi.org/10.1128/AAC.02823-14 (2014).

41. Mosmann, T. Rapid colorimetric assay for cellular growth and survival: application to proliferation and cytotoxicity assays. J. Immunol. Methods. 65 , 55-63 https://doi.org/10.1016/0022-1759(83)90303-4 (1983).

42. Batdorj, B. et al. Purification and characterization of two bacteriocins produced by lactic acid bacteria isolated from Mongolian airag. J. Appl. Microbiol. 101, 837-848 https://doi.org/10.1111/j.1365-2672.2006.02966.x. (2006).

43. Bozzola, J. J. \& Russell, L. D. Electron microscopy: principles and techniques for biologists. (Jones \& Bartlett Learning, 1999).

\section{Figures}

a

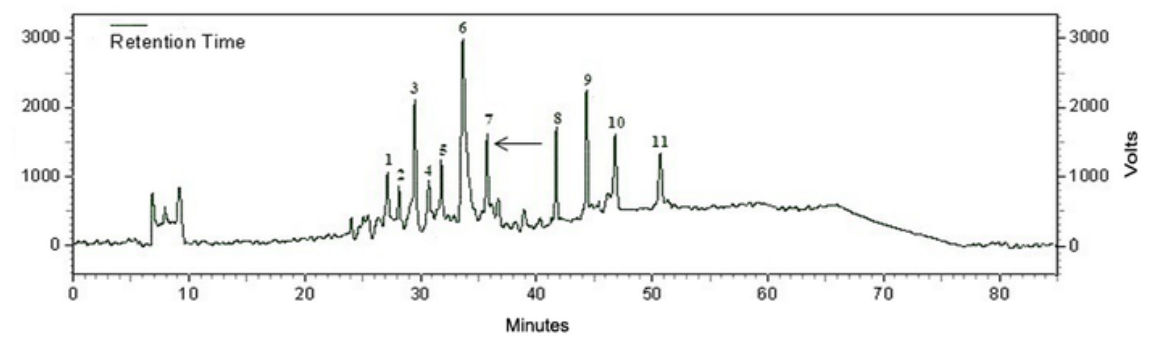

b

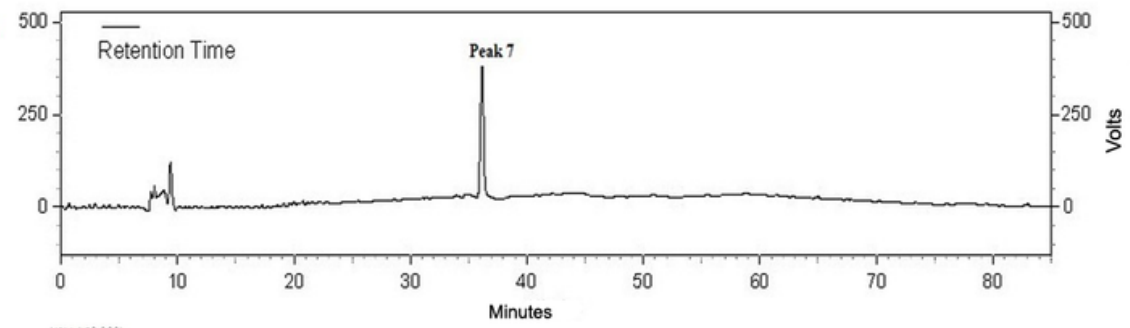

d

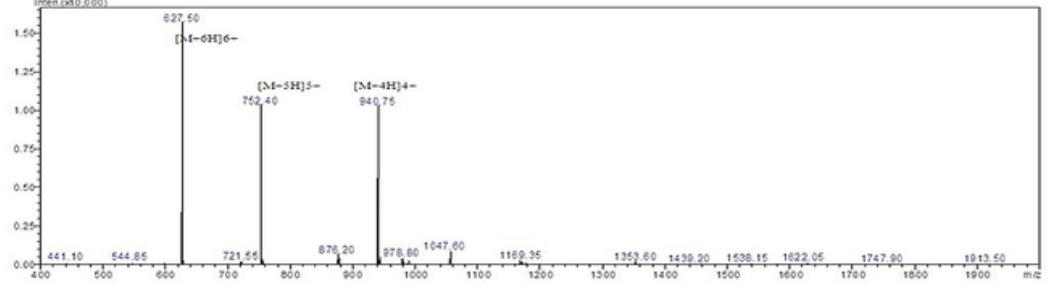

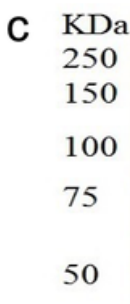

250
150
100
75
50

37

25

20

15

10

5

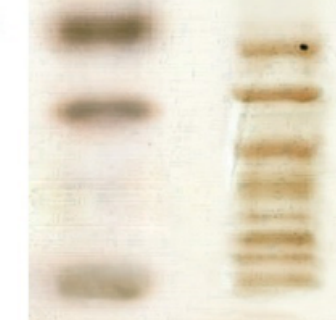

2
1

2

3

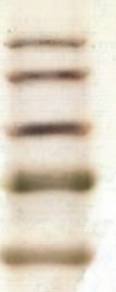

-

\section{Figure 1}

(a) Peptide RP-HPLC purification from Carum carvi seeds. The arrow shows the active peak 7. (b) The Chromatogram obtained after re-chromatography process to purify the active peak 7. (c) Tricine-SDS-PAGE profile stained with silver (1) Molecular weight markers (2-250 kDa), (2) the extracted peptide 
passing through an ultra-membrane with the cutoff of 10-kDa, and (3) the RP-HPLC column purified peak 7. (d) ESI- mass spectrum of purified antifungal peptide. Multiple charged molecular ions are indicated.
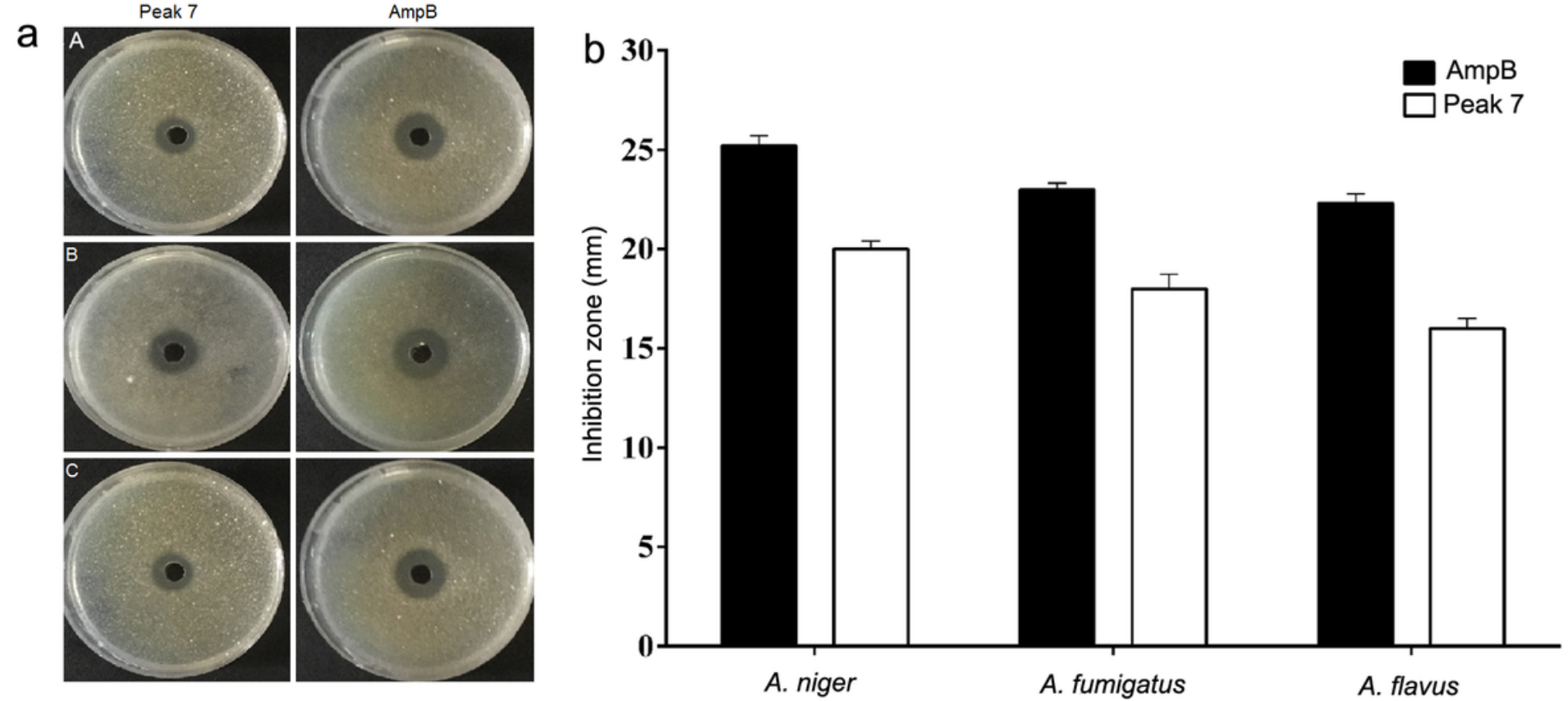

Figure 2

$(a, b)$ Antifungal effect of peak 7 against Aspergillus species was measured using radial diffusion method. (a) The inhibition zone of peak 7 and Amphotericin B against (A) A. flavus PFCC 100, (B) A. niger ATCC 9029, and (C) A. fumigatus Af293. (b) The inhibition zone diameter. Values are provided as the mean $\pm \mathrm{SD}$. 

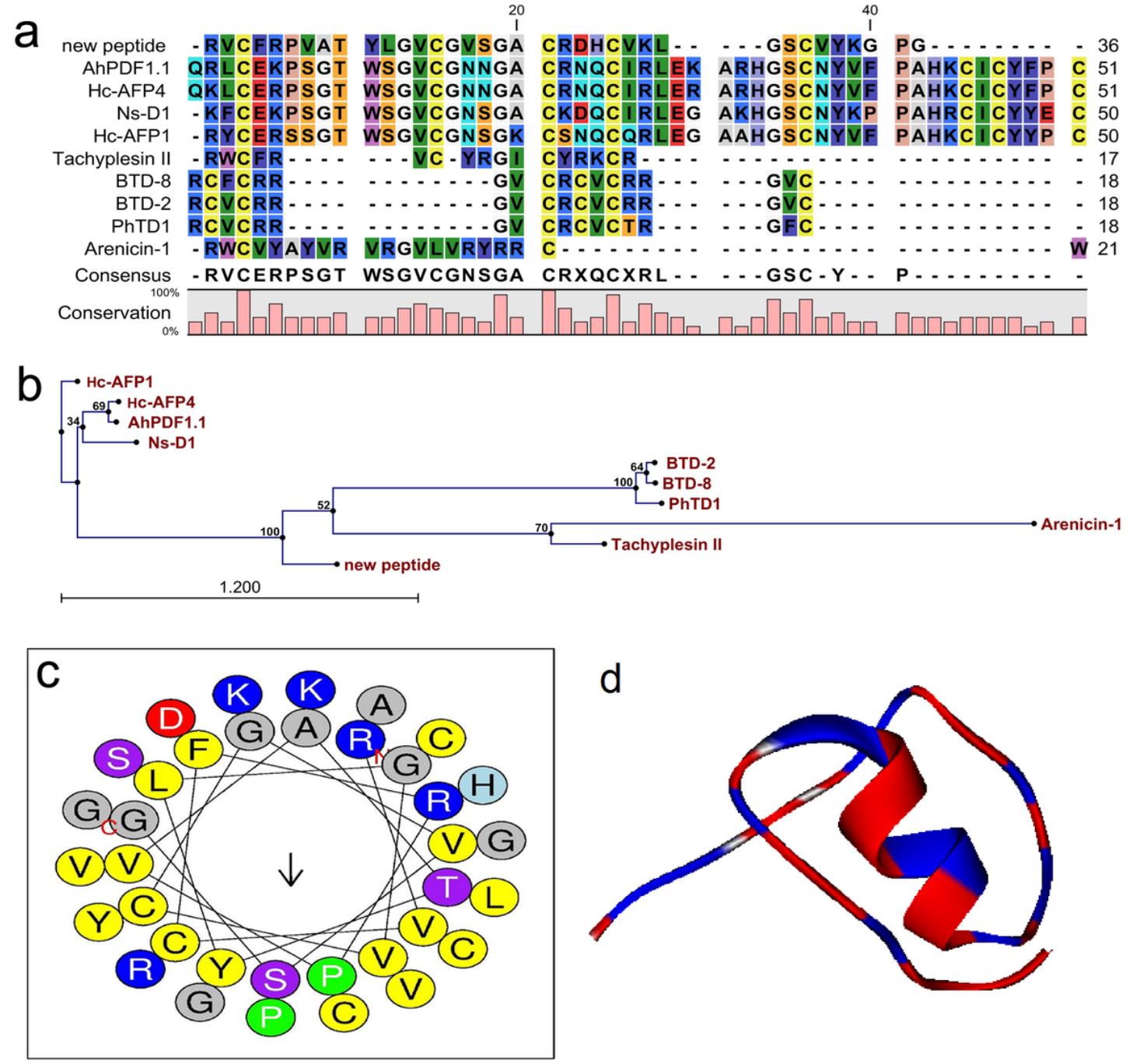

Figure 3

The alignment (a) and phylogenetic tree (b) of Cc-AFP1 peptide. (a) The alignment of Cc-AFP1 amino acid sequences as well as the sequences related to other antimicrobial peptides. (b) Phylogenetic tree of Cc-AFP1. Phylogenetic tree was acquired by CLC main workbench software. Each sequence name is written at the end of the relevant branch. The tree reliability was determined using bootstrap method with 100 replications. (c) Helical wheel diagram of CcAFP1 peptide, polar and nonpolar amino acids and their locations in peptide can be observed. (d) Three-dimensional structure model of The Cc-AFP1 with a-helix and random coil. 

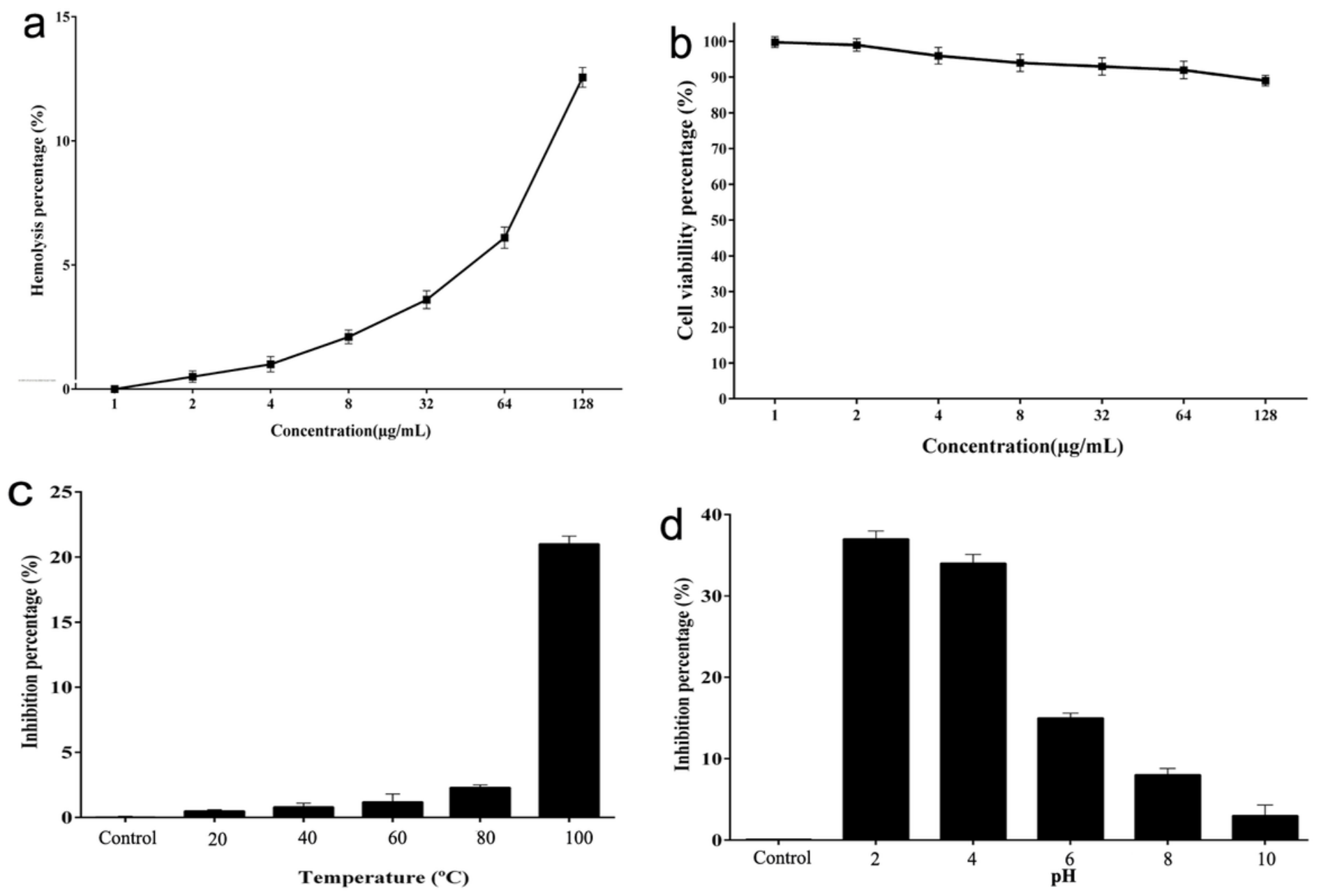

Figure 4

Hemolytic effect, cytotoxic effect and stability of Cc-AFP1. (a) Cc-AFP1 Hemolytic effect against human erythrocytes. (b) Cytotoxic effect of CcAFP1against HEK293 cells. (c, d) The temperature (c) and pH (d) effects on the antifungal effect of Cc-AFP1 against A. fumigatus cells. Values are provided as mean \pm SD. 


\section{a}

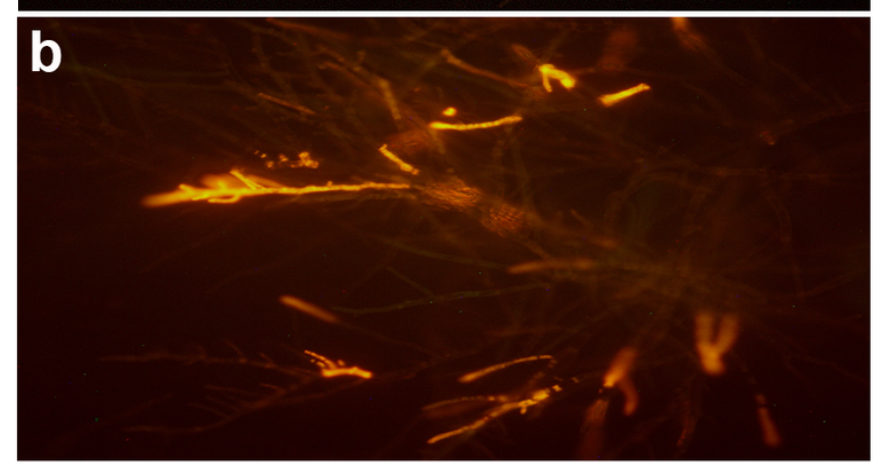

C

\section{Figure 5}

Fluorescent microscope analysis of propidium iodide uptake during the membrane permeabilization assay. (a) Fluorescent images of untreated $\mathrm{A}$. fumigatus hyphae. (b, c) fluorescent images of treated A. fumigatus hyphae with Cc-AFP1 at the concentration of 8 and $16 \mu \mathrm{g} / \mathrm{mL}$, respectively. 

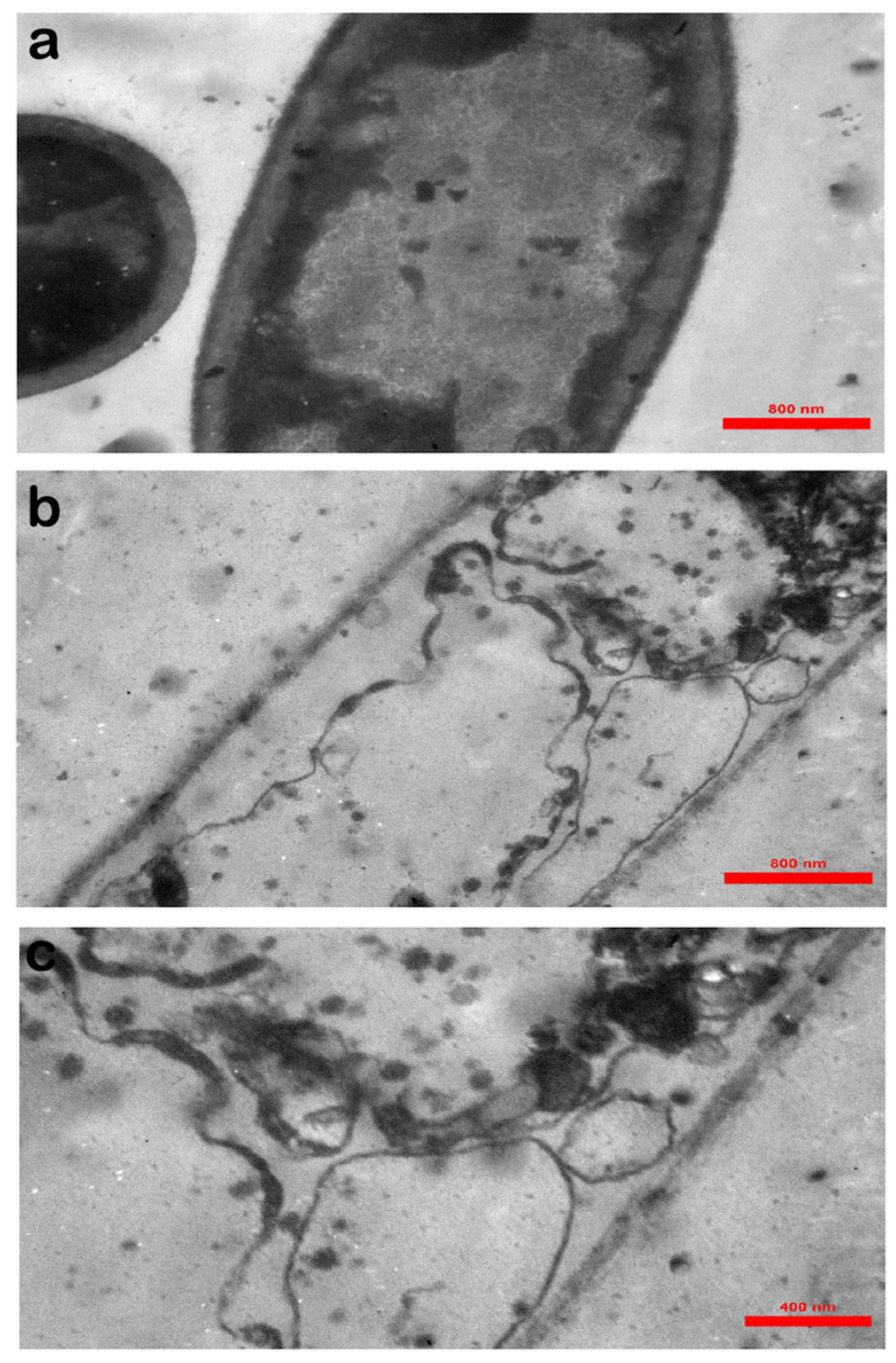

\section{Figure 6}

Transmission electron microscopy of A. fumigatus untreated and treated hyphae cells with Cc-AFP1 at the concentration of $16 \mu \mathrm{g} / \mathrm{mL}$ after $4 \mathrm{~h}$. (a) control cells; (b, c) Cc-AFP1 treated cells. The intact cytoplasmic membranes were found, and the cells were normal in the controls (a). (b, c) Cc-AFP1 damages the cytoplasmic membrane as well as cell lysis. 